Article

\title{
Interfacial Characteristics and Mechanical Properties of CuSn15/HT250 Prepared via Additive Manufacturing Combined with an Inconel 718 Interlayer
}

\author{
Huaqiang Liu ${ }^{1,2}$, Kai Guo ${ }^{1,2, *}$, Jie Sun ${ }^{1,2}$ and Hao Shi ${ }^{1,2}$ \\ 1 Key Laboratory of High Efficiency and Clean Mechanical Manufacture of MOE, School of Mechanical \\ Engineering, Shandong University, Jinan 250061, China; 202034363@mail.sdu.edu.cn (H.L.); \\ 201813930@mail.sdu.edu.cn (J.S.); shihao123@mail.sdu.edu.cn (H.S.) \\ 2 Research Centre for Aeronautical Component Manufacturing Technology and Equipment, \\ Shandong University, Jinan 250061, China \\ * Correspondence: hql8023andystar@mail.sdu.edu.cn
}

Citation: Liu, H.; Guo, K.; Sun, J.; Shi, H. Interfacial Characteristics and Mechanical Properties of CuSn15/ HT250 Prepared via Additive Manufacturing Combined with an Inconel 718 Interlayer. Materials 2021, 14, 7833. https://doi.org/10.3390/ ma14247833

Academic Editor: Antonino Squillace

Received: 6 October 2021

Accepted: 12 November 2021

Published: 17 December 2021

Publisher's Note: MDPI stays neutral with regard to jurisdictional claims in published maps and institutional affiliations.

Copyright: (c) 2021 by the authors. Licensee MDPI, Basel, Switzerland. This article is an open access article distributed under the terms and conditions of the Creative Commons Attribution (CC BY) license (https:// creativecommons.org/licenses/by/ $4.0 /)$.

\begin{abstract}
Tremendous discrepancies in the positive enthalpy of mixing and the coefficient of thermal expansion emerge between the copper alloy and the gray cast iron, accounting for numerous pores and cracks in the interfacial region during the metallurgical bonding process. To enhance the interfacial bonding properties of these two refractory materials, laser-directed energy deposition was applied to fabricate the CuSn15 alloy on the HT250 substrate; meanwhile, Inconel 718 alloy, acting as the interlayer, was added to their bonding region. Firstly, the effect of the deposition process on deposition layer quality was investigated, and then the effects of Inconel 718 addition on the interfacial morphology, element distribution, phase composition, bonding strength, microhardness were studied. The results showed that a substrate (HT250) without cracks and a deposition layer (CuSn15) free from pores could be obtained via parameter optimization combined with preheating and slow cooling processes. Adding the Inconel 718 interlayer eliminated the interfacial pores and cracks, facilitated interfacial element $(\mathrm{Cu}, \mathrm{Fe}, \mathrm{Ni})$ diffusion, and enhanced interfacial bonding strength. The interface between HT250 and CuSn15 mainly contained the FeSn 2 phase, while the interfaces of the CuSn15-Inconel 718 and the Inconel 718-HT250 were mainly composed of the $\mathrm{Ni}_{3} \mathrm{Sn}_{4}, \mathrm{Cr}_{5} \mathrm{Si}_{3}$, $\mathrm{FeSi}_{2}, \mathrm{Cr}_{7} \mathrm{C}_{3}$. The microhardness and fracture morphology of the interfacial region in the samples with and without the interlayer were also studied. Finally, CuSn15 was also successfully deposited on the surface of the HT250 impeller with large size and complex structure, which was applied in the root blower.
\end{abstract}

Keywords: laser-directed energy deposition; CuSn15; HT250; interfacial characteristic; impeller

\section{Introduction}

Gray cast iron finds extensive use in the manufacture of molds, cams, machine tool beds, impellers, etc., in various fields requiring large equipment, on account of its excellent machinability, castability, thermal conductivity, and shock absorption, as well as its cost effectiveness [1,2]. Nevertheless, under formidable conditions such as various forms of erosion and tension, components are liable to break down, resulting in enormous economic losses [3,4] and limiting the equipment's further application.

With the aim of achieving a reduction in damage caused to components, several conventional surface repair methods have been widely adopted, including TIG welding [5,6], arc welding [7,8], thermal spraying [9] and flame spray welding $[10,11]$. However, these techniques possess non-negligible disadvantages, such as being time consuming, having a large heat-affected zone and inferior bonding strength, and high degrees of dilution and distortion of the substrates. Consequently, in order to further improve repair or manufacturing quality, it is necessary to develop an innovative and effective method. 
Laser-directed energy deposition (LDED), as one of the innovative and promising additive manufacturing techniques for metal materials, offers numerous merits, including low dilution, enhanced metallurgical bonding, excellent process control, high efficiency, and so forth [12,13]. This technique is capable of depositing high-value and high-property materials, such as copper- and nickel-based alloy, on the surface of materials characterized by their inexpensiveness and inferior properties, leading it to find application in a variety of industrial fields including the aerospace, petrochemical engineering, and energy and power industries [14-16]. Accordingly, LDED has been identified as an effective method for repairing and strengthening the surface of gray cast iron through the deposition of copper- and nickel-based alloy, both of which possess superior corrosion resistance and strength. Nevertheless, for one thing, a large positive enthalpy of mixing exists between iron and copper, leading to a strong repulsion between them during the crystallization process, and eventually facilitating the generation of pores and cracks. For another, unlike ductile cast iron, gray cast iron adheres easily to gases and contaminants in the graphite sheet gap and the substrate, owing to its special flake graphite structure [17]. Additionally, gray cast iron possesses inferior ductility under ambient temperatures, and easily forms hard and brittle structures in the heat-affected zone during the LDED process. Therefore, some challenges are also presented in the repair of gray cast iron components via LDED, such as the elimination of the cracks and pores that tend to form at the bonding interface and the heat-affected zone. Li et al. [18] applied LDED to remanufacture cast iron and found the formation of cracks in the interface zone between the nickel-based alloy and the cast iron, extending to the ledeburite region. Yi et al. [19] reported that stress concentration formed easily at the graphite tip, where micro-cracks appeared during the LDED process. Tong et al. [4] enhanced the thermal fatigue resistance of gray cast iron through the laser alloying of $\mathrm{Cr}$ powders. Pores generated in the interface were more than conspicuous and were difficult to eliminate. Ocelík et al. [20] deposited thick Co-based alloy via LDED on gray cast iron, and plenty of pores and cracks developed. These defects have negative impacts on interfacial bonding strength, so some researchers have endeavored to adopt measures such as laser remelting [17,21], parameter optimization [22], preheating [23], etc., to reduce or eliminate the defects generated in the interface region during the LDED process. Nevertheless, in previous studies, there have been few reports on the effect of interlayer addition on interfacial defects and bonding characteristics. Furthermore, few studies have focused on the laser repair and modification of grey cast iron via LDED with copper-based alloy. In addition, the relevant interfacial features have also been little studied. More importantly, the laser repair and formation of gray cast iron components with large size and complex shape has not attracted considerable attention to date.

Accordingly, in this work, CuSn15 was deposited on the HT250 surface via the addition of an Inconel 718 interlayer during the LDED process. Process optimization and interfacial bonding characteristics including interfacial morphology, element distribution, phase composition, bonding strength, and microhardness were studied. Finally, CuSn15 was successfully deposited on the surface of an HT250 impeller with a large size and complex structure. This work may be of great significance in extending the application of refractory materials for LDED, as well as expanding the use of LDED in the field of petrochemical engineering, mining machinery, etc.

\section{Materials and Methods}

The substrate used in the LDED was HT250 with dimensions of $100 \mathrm{~mm} \times 100 \mathrm{~mm} \times 30 \mathrm{~mm}$. The surface of the substrate was ground and rinsed with anhydrous ethanol and acetone before LDED. CuSn15 powders (Northwest Institute for Non-Ferrous Metal Research, Xi'an, China) and Inconel 718 powders (Avimetal Powder Metallurgy Technology (Beijing) Co., Ltd., Beijing, China) were selected as the deposition materials. These two powders both possessed diameters ranging from 53 to $150 \mu \mathrm{m}$, enhancing the powder flow ability, and their morphologies and powder particle size distributions are shown in Figure 1. The chemical compositions of the Inconel 718, CuSn15 and HT250 are listed in Table 1. Before 
LDED, two kinds of powder were dried at $120^{\circ} \mathrm{C}$ for $2 \mathrm{~h}$ in the vacuum drying oven. Deposition materials were fabricated by means of a continuous fiber LDED system with a coaxial powder feeder. The laser working head, based on a coaxial powder feeder, was mounted on the 5 axis of a CNC machine, and consisted of a focusing system for the laser beam, a cooling system for the head, and a powder focusing nozzle with four powder beams. In particular, this laser working head divided the primary laser beam into three beams, and then focused them again on the material surface. The laser emission was $1080 \pm 10 \mathrm{~nm}$, with a maximum output power of $1.5 \mathrm{~kW}$ and a near Gaussian distribution beam profile. Ar gas was used to deliver the alloy powder into the molten pool via a coaxial powder feeder and to shield the molten pool from oxidization and contamination.

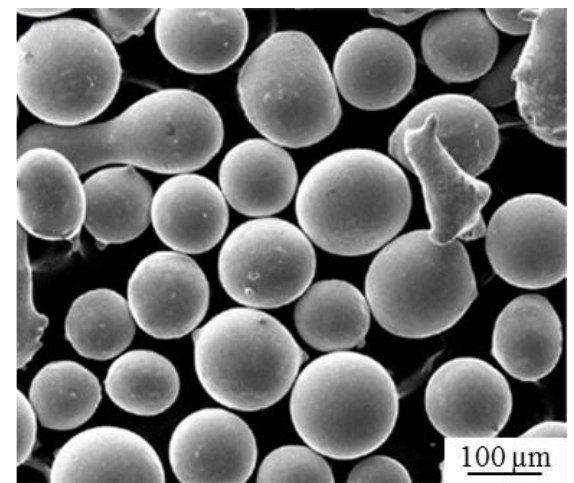

(a)

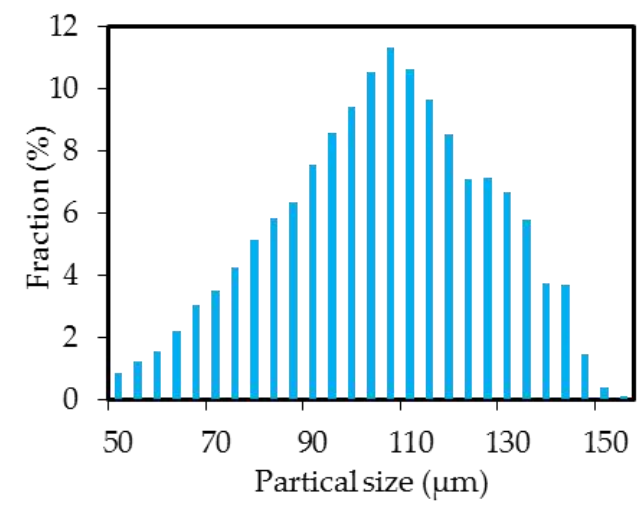

(c)

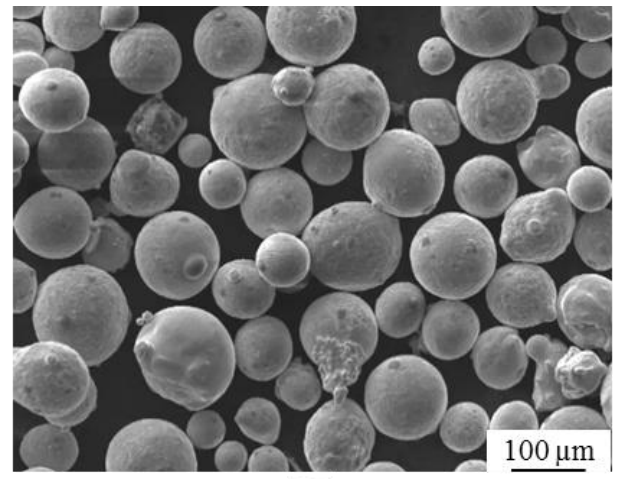

(b)

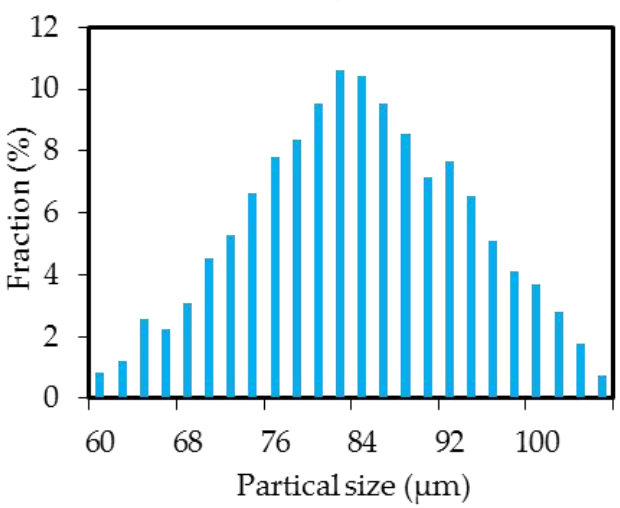

(d)

Figure 1. SEM images and powder particle size distribution of $(\mathbf{a}, \mathbf{c})$ Inconel 718 and $(\mathbf{b}, \mathbf{d})$ CuSn15.

Table 1. The chemical composition of Inconel 718, CuSn15 and HT250 for LDED (wt.\%).

\begin{tabular}{|c|c|c|c|c|c|c|c|c|c|c|c|c|c|c|}
\hline Material & $\mathrm{C}$ & Si & $\mathrm{Cr}$ & B & $\mathbf{P}$ & $S$ & Mn & $\mathrm{Cu}$ & Sn & & $\mathbf{P b}$ & $\mathbf{F e}$ & $\mathrm{Al} / \mathrm{Nb} / \mathrm{Ti} / \mathrm{Mo}$ & $\mathrm{Ni}$ \\
\hline Inconel 718 & 0.042 & - & 18.52 & - & - & - & - & - & - & - & - & 16.87 & $0.6 / 4.9 / 1.0 / 3.0$ & Bal. \\
\hline CuSn15 & - & - & - & - & - & - & - & 85.67 & 14.33 & & - & - & - & - \\
\hline НТ250 & 3.2 & 1.88 & - & - & 0.14 & 0.1 & 1.0 & - & - & - & - & Bal. & - & - \\
\hline
\end{tabular}

On the basis of the previous experimental results, the parameters applied for depositing Inconel 718 were optimized with respect to surface quality, dilution rate, aspect ratio and microhardness. Therefore, only parameter optimization for the deposition of CuSn15 was implemented in this work, aiming at surface evenness and the number of pores. The parameters for the deposition of Inconel 718 and CuSn15 are listed in Table 2. During the LDED process, the Inconel 718, as an interlayer, was first deposited on the surface of HT250, and then CuSn15 was fabricated on the surface of Inconel 718. Additionally, a preheating process at a temperature of approximately $300{ }^{\circ} \mathrm{C}$ and a slow cooling process with a cooling rate of $5 \sim 10^{\circ} \mathrm{C} / \mathrm{min}$ were also carried out via an electronic multi-purpose furnace during 
the LDED process prevent the emergence of cracks in the HT250 substrate. The LDED process was always performed within the electronic multi-purpose furnace to make sure there were no sudden drops in the temperature of the deposition layers.

Table 2. Parameters for the LDED process.

\begin{tabular}{cccccc}
\hline Material & No. & $\begin{array}{c}\text { Laser Power } \\
\text { P/(W) }\end{array}$ & $\begin{array}{c}\text { Scanning Speed } \\
\text { V/(mm/s) }\end{array}$ & $\begin{array}{c}\text { Powder Feeding Rate } \\
\text { F/(g/min) }\end{array}$ & $\begin{array}{c}\text { Overlapping } \\
\text { Rate O/(\%) }\end{array}$ \\
\hline Inconel 718 & 0 & 1500 & 13.3 & 16.7 & 37.7 \\
\hline \multirow{2}{*}{ CuSn15 } & 1 & & 6.7 & & 37.7 \\
& 3 & 1500 & 10.0 & 16.7 & \\
\hline
\end{tabular}

The samples used for microstructure characterization were divided into sections using an electro-discharge cutting machine. In addition, these samples were subsequently subjected to grinding and polishing. Microstructure was investigated via an Optical Microscope (SOIF-6XB, SOIT, Shanghai, China), Field Emission Scanning Electron Microscopy employing Energy Dispersive Spectroscopy (JSM-7800F, JEOL, Tokyo, Japan), and X-ray Diffraction (D8 Advance, Bruker, Germany). For the X-ray Diffraction analysis, MDI Jade software was used to analyze the phase composition in the interfacial region. Furthermore, during the testing process, the database of the Joint Committee on Powder Diffraction Standards (JCPDS) was also used to identify the phase composition.

The interfacial bonding strength between the deposition layer and the substrate was determined using a CMT-30 electronic universal testing machine with a constant strain rate of $0.02 \mathrm{~min}^{-1}$ at ambient temperature. The tensile experiment was based on the ASTM standard E8/E8M-16a. An illustration of the tensile samples is presented in Figure 2. Moreover, microhardness measurements were performed according to the ASTM standard E384-17 on a transverse cross-section of the deposited zone using a Vickers hardness tester (MH-6). Microhardness measurements were obtained at intervals of $0.1 \mathrm{~mm}$ under a load of $100 \mathrm{~g}$ for $15 \mathrm{~s}$. The microhardness results reported are the average values obtained from the 21 measurements.

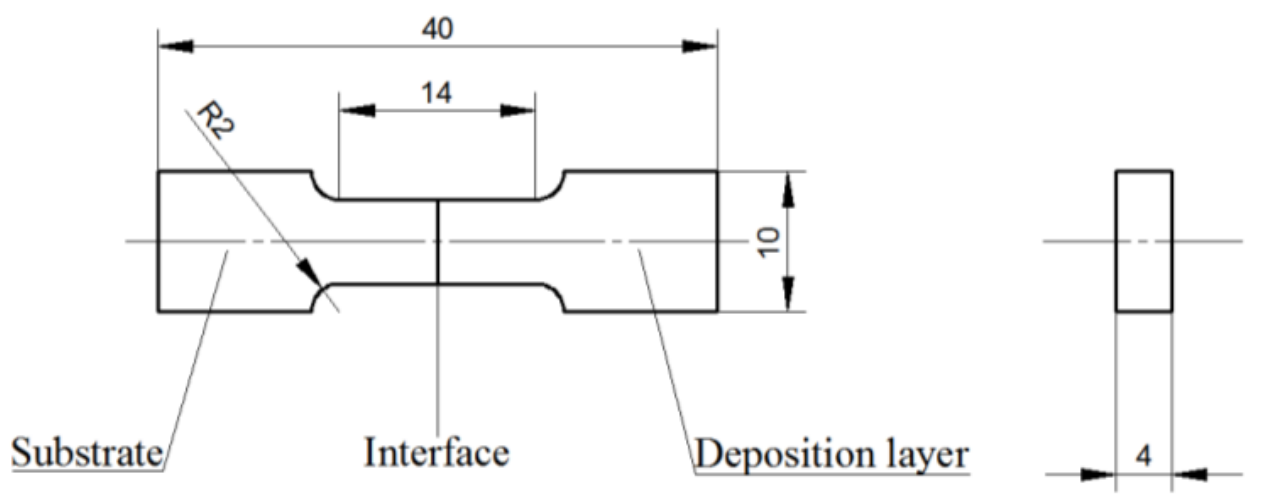

Figure 2. Illustration of tensile samples for testing bonding strength.

\section{Results and Discussion}

\subsection{Process Optimization}

Figure 3 presents the morphology of the deposition layers obtained via the preheating (approximately $300{ }^{\circ} \mathrm{C}$ ) and slow cooling $\left(5 \sim 10^{\circ} \mathrm{C} / \mathrm{min}\right.$ ) processes with varying scanning speeds. Without the preheating and slow cooling processes, the CuSn15 and Inconel 718 deposition layers were both desquamated from the surface of HT250, also indicating that cracks occurred in the heat-affected zone of HT250, as shown in Figure 3a. Nevertheless, deposition layers with excellent bonding quality and free from cracks were obtained as a result of the preheating and slow cooling processes, as depicted in Figure 3b. To 
further investigate the effect of the parameters on the quality of the deposition layer, parameter optimization was also carried out with respect to the preheating and slow cooling processes. Figure $3 \mathrm{c}$ shows the morphology of the CuSn15 deposition layers obtained with varying scanning speeds $(\mathrm{V})$. The deposition layers obtained at scanning speeds of 10.0 and $13.3 \mathrm{~mm} / \mathrm{s}$ exhibited smoother surfaces compared to those obtained at 6.7 and $16.7 \mathrm{~mm} / \mathrm{s}$. Moreover, a lot of pores emerged in the deposition layers obtained with scanning speeds of $6.7,13.3$, and $16.7 \mathrm{~mm} / \mathrm{s}$, and the corresponding numbers of pores $(\mathrm{N})$ were 3,11 , and 16 , respectively. However, no striking pores appeared in the deposition layer obtained at the scanning speed of $10.0 \mathrm{~mm} / \mathrm{s}$. Therefore, based on the number of pores and the surface evenness, superior deposition layer quality could be obtained with a scanning speed of $10.0 \mathrm{~mm} / \mathrm{s}$. Figure $3 \mathrm{~d}$ shows the deposited CuSn15 with large area and different layers obtained through the application of the following parameters: $\mathrm{V}=10.0 \mathrm{~mm} / \mathrm{s} ; \mathrm{P}=1500 \mathrm{~W} ; \mathrm{F}=16.7 \mathrm{~g} / \mathrm{min} ; \mathrm{O}=37.7 \%$. In addition, no defects were found on the surface of either deposition layer.

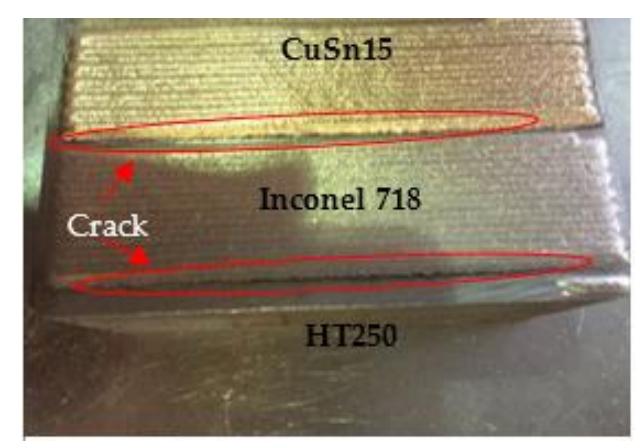

(a)

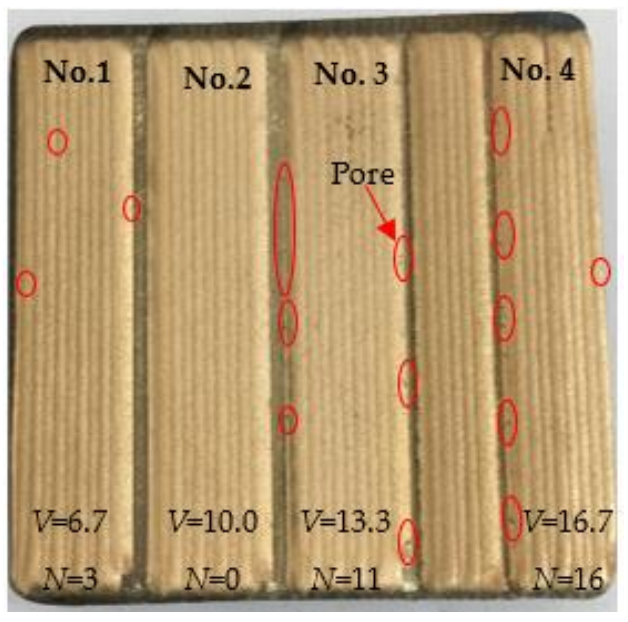

(c)

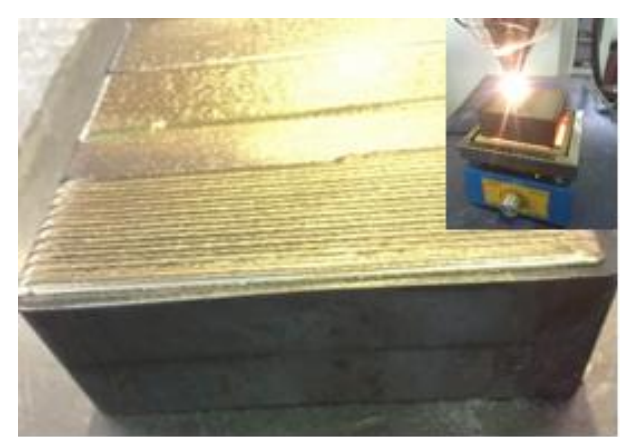

(b)

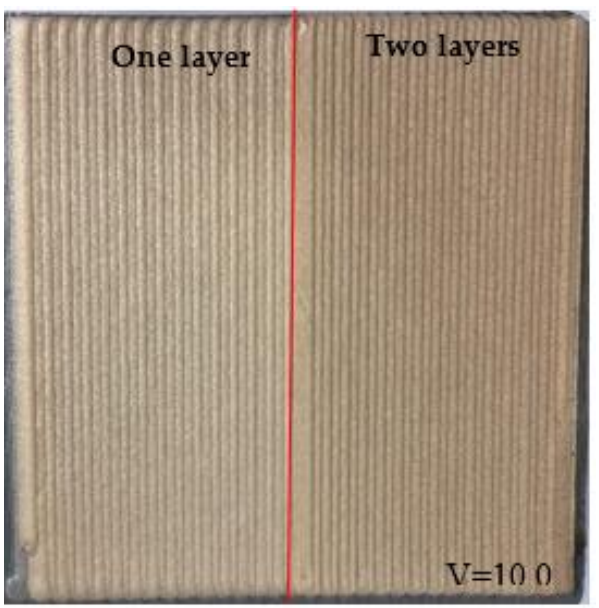

(d)

Figure 3. The morphology of the deposition layer. (a) Deposition layer obtained in the absence of heat; (b) deposition layer obtained under the conditions of preheating $\left(300^{\circ} \mathrm{C}\right)$ and slow cooling; (c) CuSn15 obtained via various scanning speeds; (d) CuSn15 with large area obtained with a scanning speed of $10.0 \mathrm{~mm} / \mathrm{s}$. Note: "V" denotes scanning speed and “ $\mathrm{N}$ " means the number of pores.

HT250 possessed inferior ductility under ambient temperature. In addition, the tensile strengths of CuSn15 and Inconel 718 were superior to that of HT250, making it easier for HT250 to be torn apart during the LDED process. Accordingly, the preheating and slow cooling processes could improve the ductility and reduce the formation of the hard and brittle HT250 structure in. More importantly, the process of preheating and slow cooling is flexible in terms of application. For instance, heating bars or electromagnetic heating systems with variable size and adjustable temperature can be applied to achieve 
the preheating and slow cooling of HT250 parts of larger size during the LDED process, just like the above-mentioned HT250 impeller we manufactured.

There are impurities and oil contaminants in the gray cast iron caused by the primary casting process. These contaminants and impurities were heated and even burned during the LDED process; therefore, gases were generated, facilitating the formation of pores [24]. CuSn15 is mainly composed of $\mathrm{Cu}$ and $\mathrm{Sn}$ elements, and there is a huge discrepancy between the melting points of $\mathrm{Cu}\left(1083.4^{\circ} \mathrm{C}\right)$ and $\mathrm{Sn}\left(231.89^{\circ} \mathrm{C}\right)$, leading to a phenomenon whereby the evaporation of the $\mathrm{Sn}$ element easily accelerates the formation of pores during the LDED process. Furthermore, higher scanning speed $(13.3,16.7 \mathrm{~mm} / \mathrm{s})$ made it more difficult for gasses, such as $\mathrm{O}_{2}$ and Ar, to escape from the molten pool, resulting in the formation of pores [25]. Additionally, as shown in Figure 3a, a large number of pores were always distributed in the initial and final single-pass deposition layers, which can be attributed to the fact that the pores in the previous single-pass layer were covered by the subsequent layer.

\subsection{Interfacial Characteristics}

\subsubsection{Interfacial Morphology}

Figure 4 displays the morphology of the deposition layer and the corresponding interface. The CuSn15 deposition layer and the Inconel 718 interlayer were both smooth, with no remarkable pores and cracks, as shown in Figure 4a. In the sample without the interlayer, cracks with lengths of approximately $625 \mu \mathrm{m}$ and pores with diameters of approximately $10 \mu \mathrm{m}$ appeared in the vicinity of the interface, as shown in Figure $4 \mathrm{~b}$. In the sample with the Inconel 718 interlayer, the interface between the CuSn15 and the Inconel 718 was extremely straight, and no pores or cracks occurred, as shown in Figure 4c. Furthermore, based on Figure 4d, the interface between Inconel 718 and HT250 turned into an indistinct region where there was also no defect, indicating that Inconel 718 and HT250 exhibited excellent metallurgical bonding.

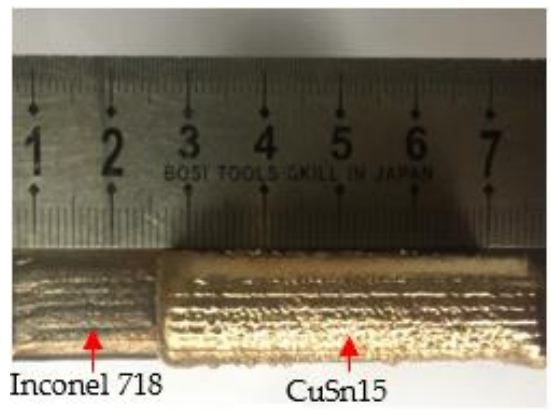

(a)

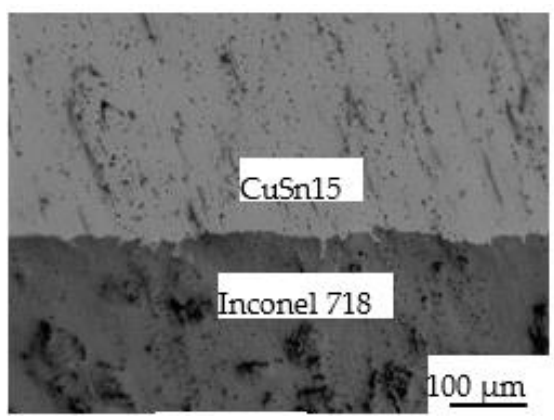

(c)

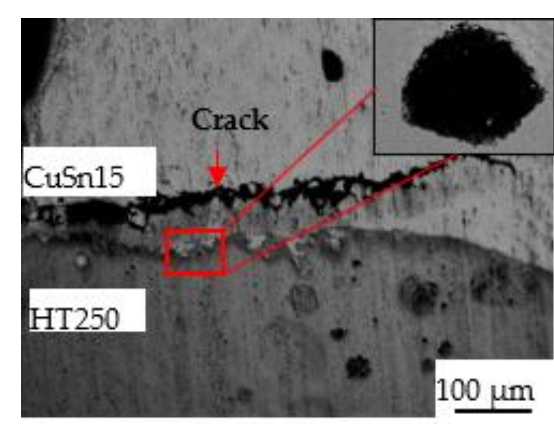

(b)

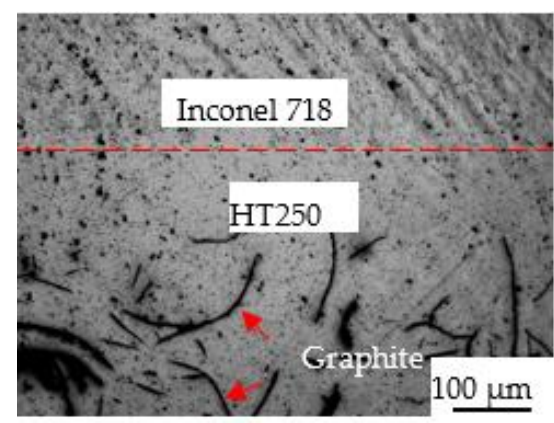

(d)

Figure 4. The morphology of the deposition layer and the relevant interface. (a) Inconel 718 and CuSn15; (b) the interface between CuSn15 and HT250; (c) the interface between CuSn15 and Inconel 718; (d) the interface between Inconel 718 and HT250. 
There is a large positive enthalpy of mixing between $\mathrm{Fe}$ and $\mathrm{Cu}$, accounting for the occurrence of a strong repulsion between them during the crystallization process [26]. Additionally, a conspicuous discrepancy in the coefficient of thermal expansion between Fe and $\mathrm{Cu}$ and the inferior wettability of the cast iron could both facilitate the generation of cracks, pores and other defects. Accordingly, for the sample without the interlayer, plenty of defects appeared approaching the interface. When the Inconel 718 interlayer was added in the bonding area between the CuSn15 and the HT250, the discrepancy in the coefficient of thermal expansion was reduced. In addition, Inconel 718, as a typical nickel-based alloy, exhibited superior wettability on the CuSn15 and the HT250. Therefore, the sample with the Inconel 718 interlayer exhibited outstanding interfacial bonding qualities. It is worth pointing out that the microstructure of the HT250-Inconel 718 interface (or other interfaces) was easily affected by the slow cooling process and the thermal cycles during the LDED process. Li [27] found that the interfacial region between the cast iron and the Ni-based alloy underwent various tempering processes during the multi-LDED process, and the low cooling rate combining with thermal cycles led to the formation of a bainite structure in the interfacial region.

\subsubsection{Interfacial Element Distribution}

(1) Interface between CuSn15 and HT250

According to Table 1, CuSn15 is free of Fe and Si elements, and HT250 is without $\mathrm{Cu}$ and $\mathrm{Sn}$ elements. Consequently, $\mathrm{Fe}, \mathrm{Cu}, \mathrm{Sn}$ and $\mathrm{Si}$ elements can be used to analyze the typical element distribution close to the interface between CuSn15 and HT250. Figure 5 illustrates the element distribution in the interface region between CuSn15 and HT250. It can be seen in Figure $5 b$ that the distribution of the $\mathrm{Cu}$ and Fe elements changed dramatically through the interface. Only a small quantity of $\mathrm{Cu}$ elements emerged on the side of the HT250, and only a small amount of Fe elements appeared on the side of the CuSn15, suggesting that $\mathrm{Cu}$ and Fe elements both underwent diffusion over a short distance along the interface. In addition, the short-distance diffusion of the $\mathrm{Cu}$ and Fe elements signified that elements from the CuSn15 and the HT250 possessed inferior diffusion capability across the interface without the interlayer. The EDS mapping presented in Figure $5 c, d$ also strikingly confirms this phenomenon, which can be attributed to the fact that strong repulsion took place between the $\mathrm{Cu}$ and Fe elements during the solidification of the molten pool due to the huge difference in positive enthalpy between these two elements. Compared to the $\mathrm{Cu}$ and Fe elements, the $\mathrm{Sn}$ and $\mathrm{Si}$ elements on both sides of the interface were diffused freely and moved a longer distance, as shown in Figure 5e,f, indicating that there was no other repulsion resistance blocking the diffusion of the Sn and Si elements.

\section{(2) CuSn15-Inconel 718 and Inconel 718-HT250 Interfaces}

According to Table 1, Inconel 718 has adequate amounts of the Ni element and is free of the $\mathrm{Cu}$ and Sn elements, while CuSn15 is rich in the $\mathrm{Cu}$ and Sn elements and contains no $\mathrm{Ni}$ element. Consequently, the distributions of these elements in the vicinity of the interface can be explicitly obtained using EDS line scanning and mapping. Figure 6 shows the $\mathrm{Cu}$, $\mathrm{Ni}$, and $\mathrm{Sn}$ element distributions in the interface between CuSn15 and Inconel 718. The $\mathrm{Cu}, \mathrm{Sn}$ and $\mathrm{Ni}$ elements approaching the interface were distributed in a gradient form. Dilution occurred between the CuSn15 and the Inconel 718, implying that the diffusion of each element emerged to a certain extent. Therein, the Cu element from CuSn15 was still present at the side of the Inconel 718 interlayer, $35 \mu \mathrm{m}$ away from the interface, indicating that the diffusion distance of the $\mathrm{Cu}$ element was much longer. In addition, the diffusion results for the $\mathrm{Ni}$ element in the Inconel 718 was also similar to those obtained for the $\mathrm{Cu}$ element. Moreover, the $\mathrm{Cu}, \mathrm{Sn}$, and Ni elements were uniformly distributed immediately after crossing the interface, indicating that there was a drastic mass transfer movement of molten liquid near the interface, leading to the rapid homogenization of elements entering the molten pool $[28,29]$. 


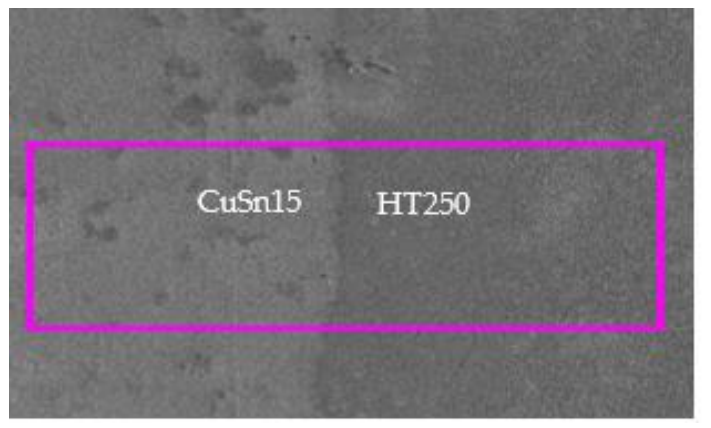

(a)

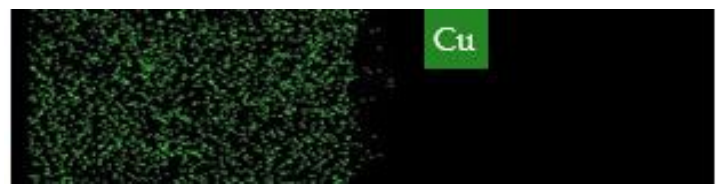

(c)

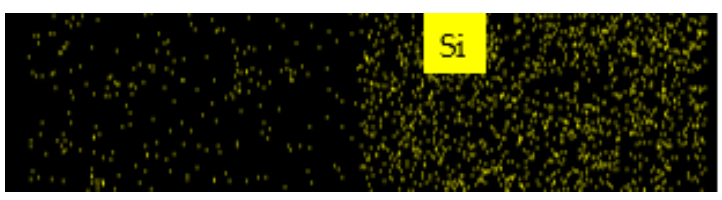

(e)

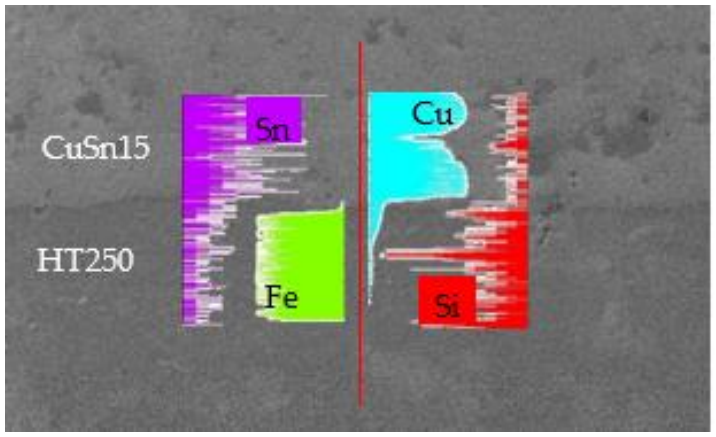

(b)

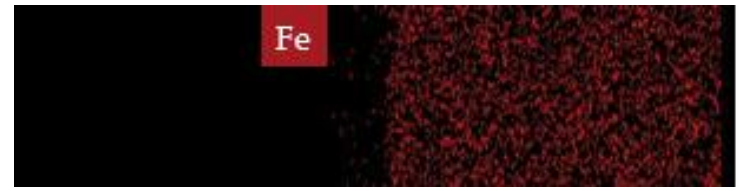

(d)

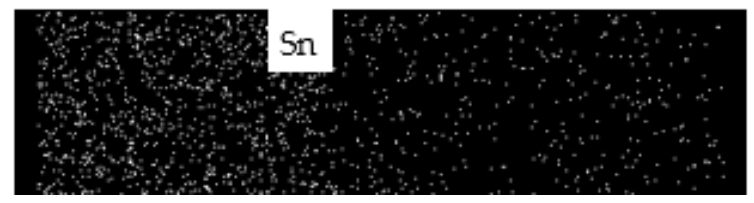

(f)

Figure 5. Element distribution in the interface between CuSn15 and HT250 obtained by EDS. (a) Mapping region; (b) line scanning region and $\mathrm{Cu}, \mathrm{Fe}, \mathrm{Sn}$, and $\mathrm{Si}$ element distribution; (c-f) $\mathrm{Cu}, \mathrm{Fe}, \mathrm{Si}$, and $\mathrm{Sn}$ element distribution in region (a).
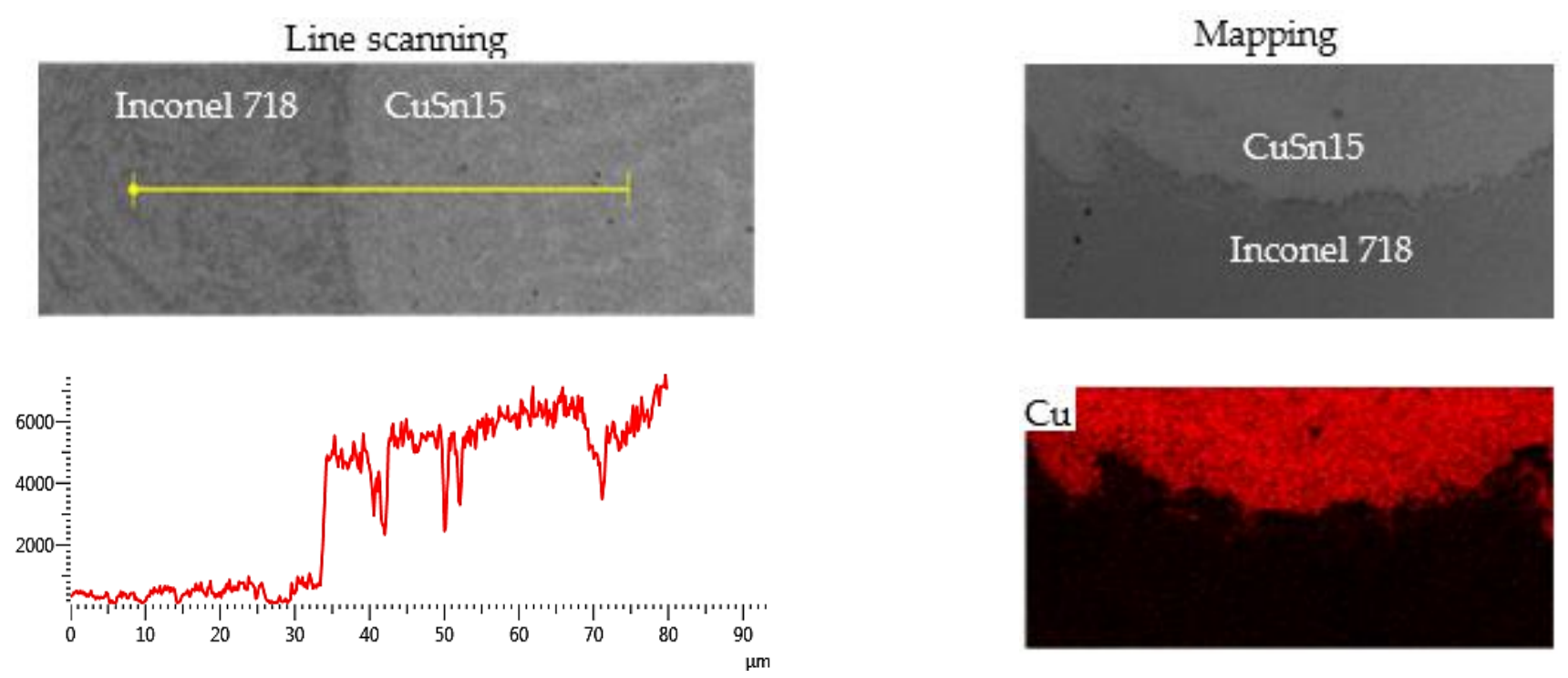

Figure 6. Cont. 

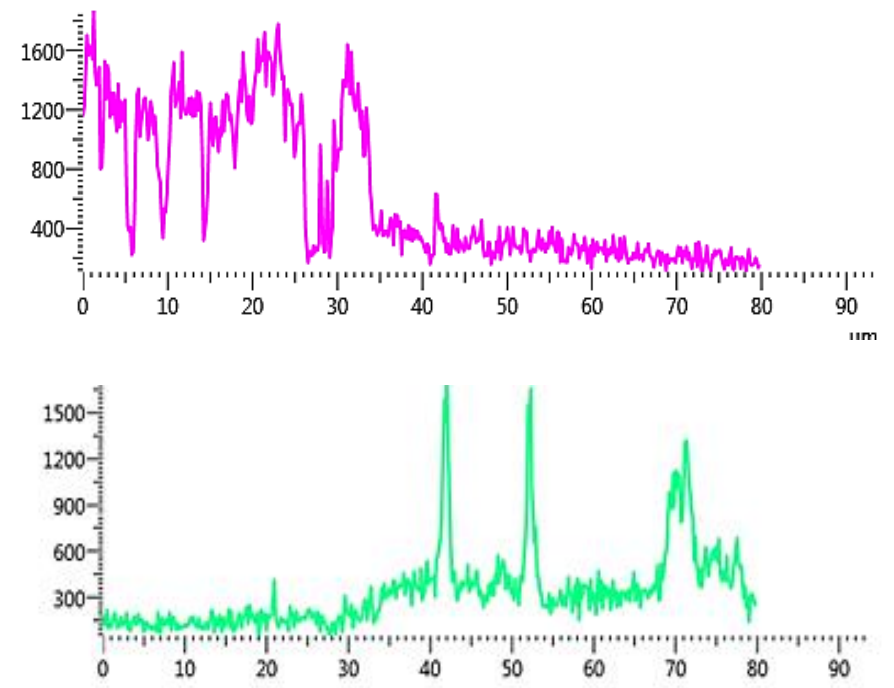
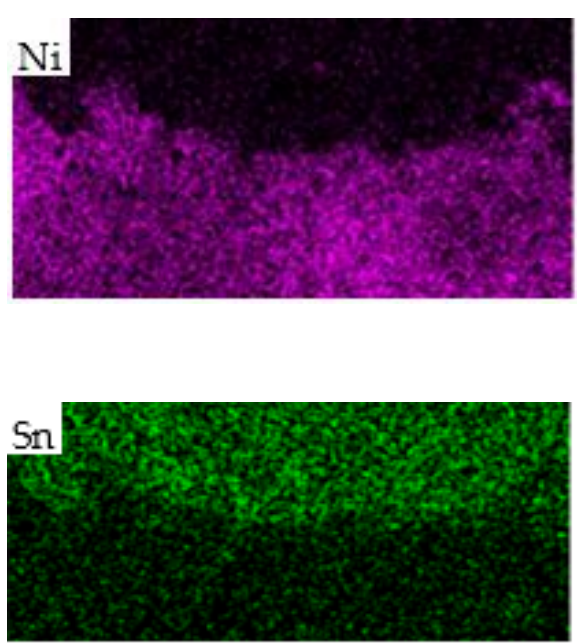

Figure 6. Element distribution in the interface between CuSn15 and Inconel 718 obtained by EDS.

(3) Interface between Inconel 718 and HT250

As shown in Table 1, HT250 contains no Ni or Cr elements, while the C content is much higher than that of Inconel 718. Ni, Cr, and C element distributions in the interface between the Inconel 718 and the HT250 are shown in Figure 7. The diffusion of the Ni and $\mathrm{Cr}$ elements from the Inconel 718 to the HT250 took place, and these elements were still present on the side of the HT250, $46 \mu \mathrm{m}$ away from the interface. The C element was more homogeneously distributed on both sides of the interface. In addition, the $C$ element was mainly present in the HT250 in graphite form. During the LDED process, the HT250 surface decarbonized slightly under the heat effect, making it easier for C element to enter the molten pool of the Inconel 718, and eventually remained in the Inconel 718 following cooling.
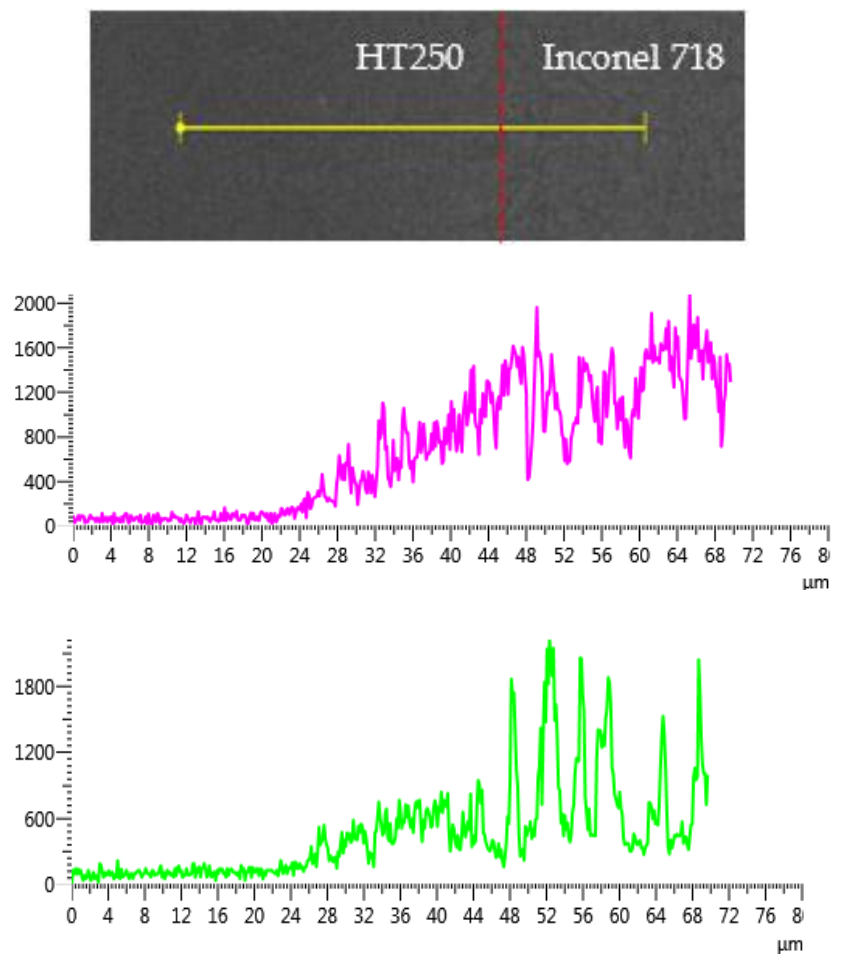
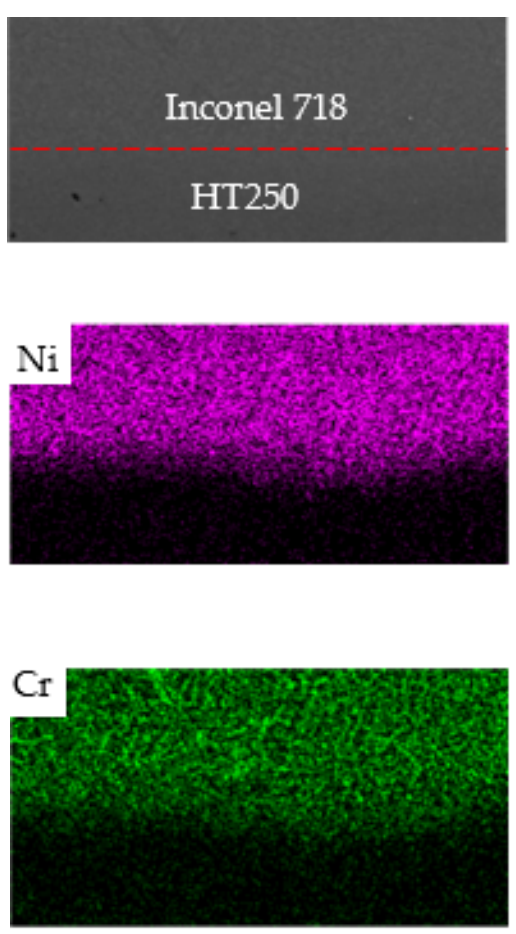

Figure 7. Cont. 

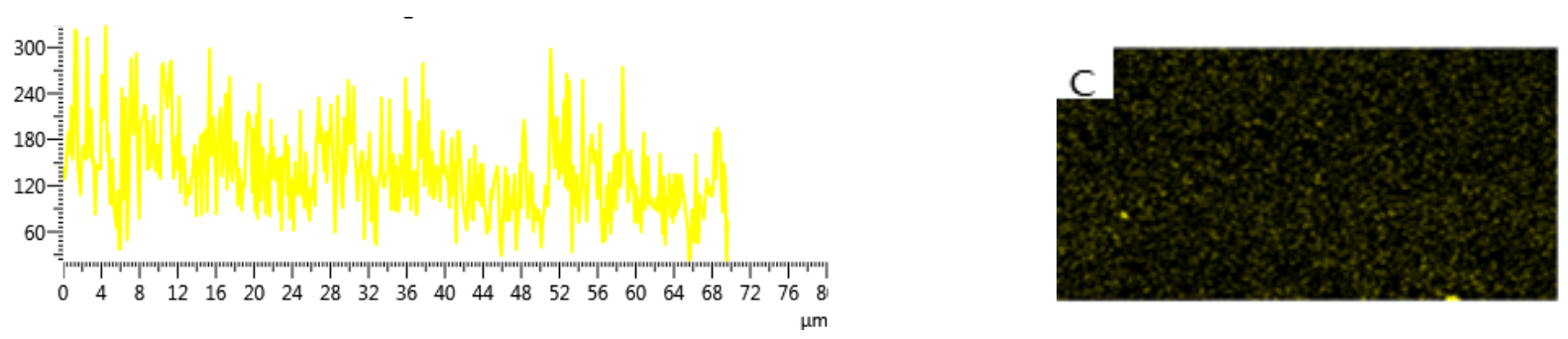

Figure 7. Element distribution in the interface between Inconel 718 and HT250 obtained by EDS.

\subsubsection{Interfacial Phases}

Figure 8 shows the $\mathrm{X}$-ray diffraction patterns of the interfacial regions. For the samples without interlayer, the interface region was composed of $\mathrm{FeSn}_{2}, \mathrm{Cu}_{81} \mathrm{Sn}_{22}$ and $\alpha$-Fe, as illustrated in Figure 8a. The FeSn 2 emerging in the interfacial region was formed by the diffusion of Fe and $\mathrm{Sn}$ elements across the interface, while the $\mathrm{Cu}_{81} \mathrm{Sn}_{22}$ and $\alpha$-Fe originated from the CuSn15 deposition layer and the HT250 substrate, respectively. Figure $8 \mathrm{~b}$ presents the XRD pattern of the interfacial regions in the samples with the Inconel 718 layer. With reference to the chemical compositions of CuSn15, Inconel 718 and HT250, as listed in Table 1, it was possible to determine typical phases in the different interface regions. $\mathrm{Ni}_{3} \mathrm{Sn}_{4}$ appeared at the interface region between $\mathrm{CuSn} 15$ and Inconel 718, and $\mathrm{Cr}_{5} \mathrm{Si}_{3}, \mathrm{Cr}_{7} \mathrm{C}_{3}, \mathrm{FeSi}_{2}$ emerged in the interface region between the Inconel 718 and the HT250, all of which originated from the diffusion of the $\mathrm{Fe}, \mathrm{Cr}, \mathrm{Cu}$, and $\mathrm{Sn}$ elements across the interface. For the other phase, $\mathrm{Cu}_{51.68} \mathrm{Sn}_{12.07}$ was derived from the CuSn15 deposition layer.
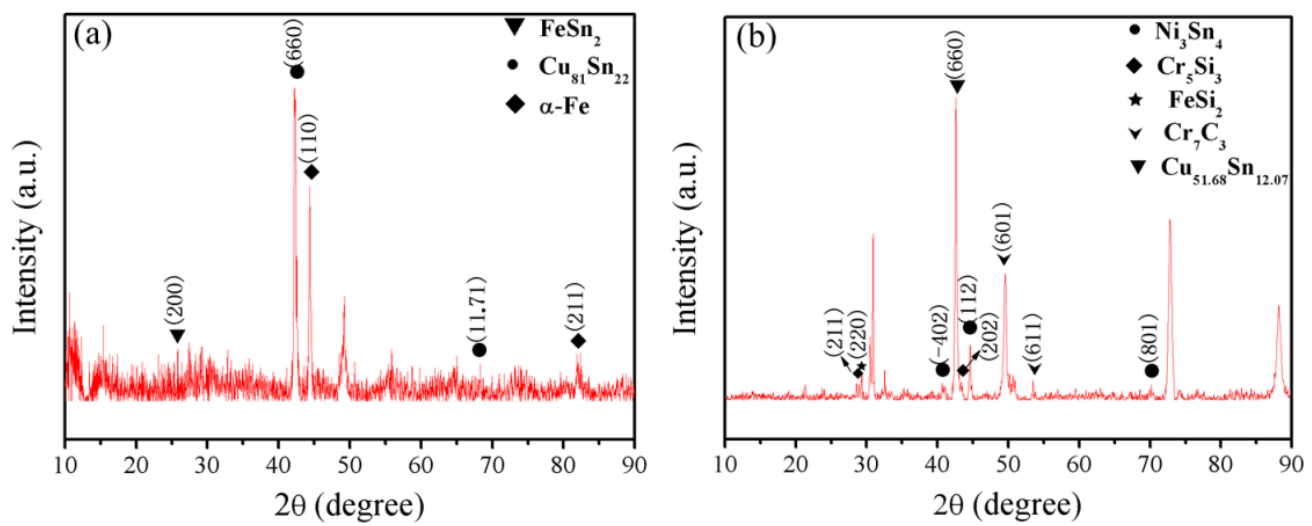

Figure 8. X-ray diffraction patterns of the interfacial regions in the samples (a) without interlayer and $(\mathbf{b})$ with interlayer.

\subsection{Interfacial Bonding Strength \\ 3.3.1. Bonding Strength}

Figure 9 presents the morphologies of the tensile samples that were used for the bonding strength test. Before the test, the tensile samples with the Inconel 718 interlayer all exhibited an obvious interface between the deposition layer and substrate, as shown in Figure 9a,b. After the test, the fracture positions of the samples without the interlayer were located in the interface region, as shown in Figure 9c. Nevertheless, as can be seen in Figure 9d, the fracture of the samples with the Inconel 718 interlayer occurred in the substrate region, where the fracture position was approximately $1 \mathrm{~mm}$ away from the interface, indicating that the actual bonding strength exceeded the tensile strength obtained for these two samples. The bonding strength of the samples is shown in Figure 10. The samples with the Inconel 718 interlayer possessed the most excellent bonding strength (above $303.75 \mathrm{MPa}$ ), while the samples without interlayer displayed a lower bonding strength (200.1 MPa). As a consequence, adding Inconel 718 interlayer could facilitate the enhancement of the bonding strength, which increased by $103.65 \mathrm{MPa}$. 


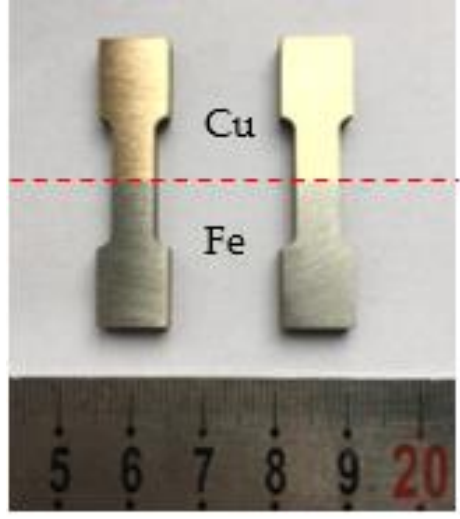

(a) Before test

Without interlayer

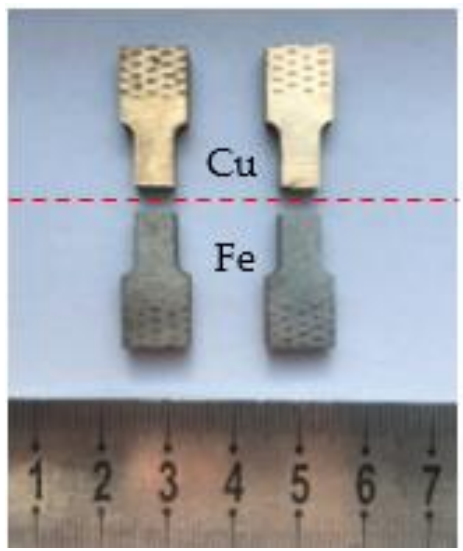

(c) After test

Without interlayer

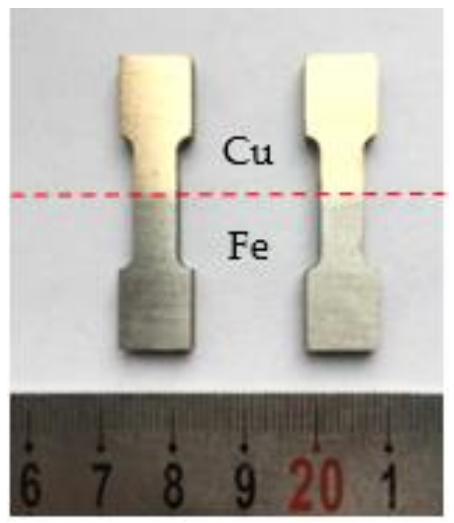

(b) Before test

Inconel 718 interlayer

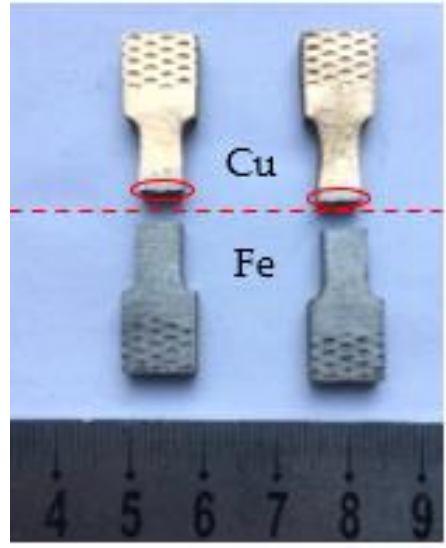

(d) After test

Inconel 718 interlayer

Figure 9. The morphology of the tensile samples without interlayer $(\mathbf{a}, \mathbf{c})$ and with Inconel 718 interlayer $(\mathbf{b}, \mathbf{d})$ before and after testing. Note: The thickness of the Inconel 718 interlayer was so small (approximately $0.7 \mathrm{~mm}$ ) that the Inconel 718 interlayer is not clearly demonstrated in the above figure.

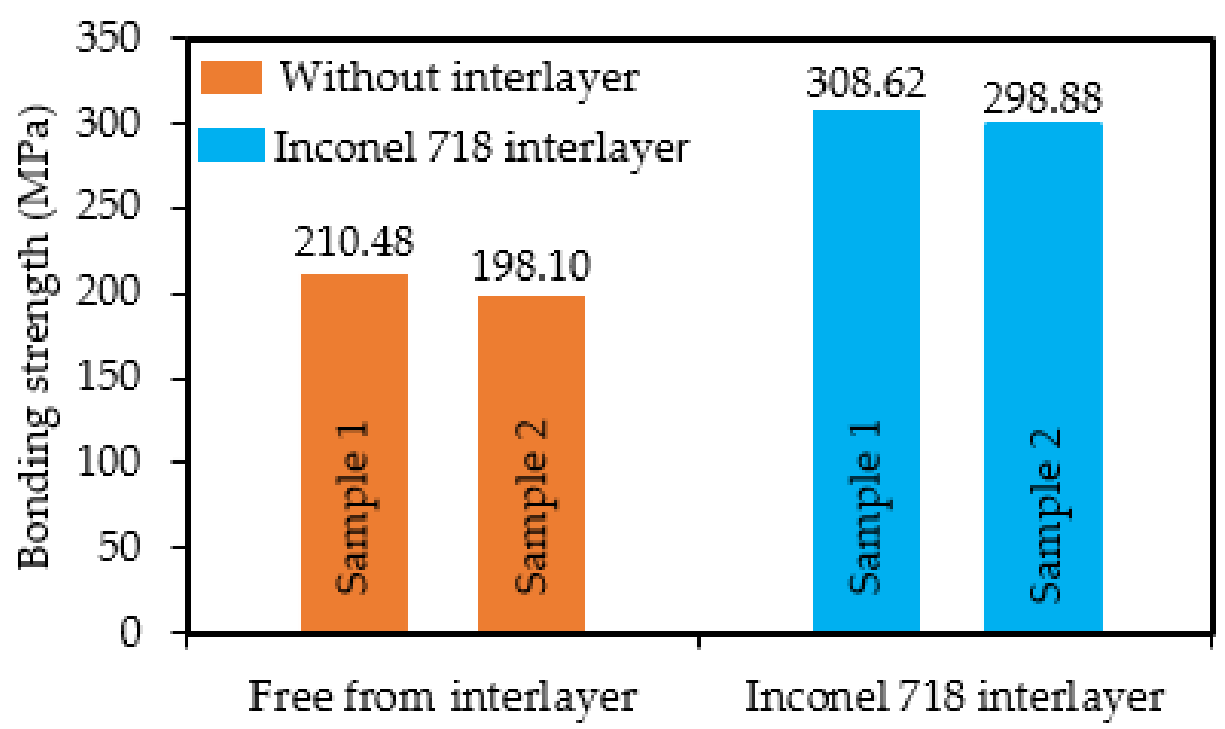

Figure 10. Bonding strength of samples with the Inconel 718 interlayer and without interlayer. 
Defects, including micropores and microcracks, in the deposited samples can primarily be attributed to the degradation in tensile strength (bonding strength). For the samples without interlayer, the interfacial regions were enriched with pores and cracks, resulting in inferior bonding strength. For the samples with the Inconel 718 interlayer, the interface was smooth and exhibited no conspicuous defects. Accordingly, superior bonding strength can be obtained via the addition of an Inconel 718 interlayer between the CuSn15 and the gray cast iron.

\subsubsection{Fracture Morphology}

Figure 11 shows the fracture morphology of the tensile samples without the interlayer and with the Inconel 718 interlayer. For the samples without the interlayer, the fracture surface was composed of a $\mathrm{Cu}$ region and an Fe region as a function of EDS mapping, as reflected in Figure 11a, further suggesting that fracture occurred in the interfacial region between the CuSn15 and HT250. The interfacial region was flat and smooth, and no prominent tearing or plastic deformation could be observed, as shown in Figure 11b, indicating that the fracture could be characterized as a brittle fracture. Furthermore, as shown in Figure 11b, some cracks emerged on the fracture surface, signifying that inferior bonding quality was obtained in the absence of the interlayer. For the samples with the Inconel 718 interlayer, for the fracture appearing on the side of the HT250, the morphology of the fracture surface of HT250 is shown in Figure 11c,d. The fracture consisted of a flat region located in the central position and an irregular position located in the edge region, as shown in Figure 11c. Moreover, tearing ridges emerged in the fracture, demonstrating that HT250 possessed a typical brittle fracture following the tensile testing process [30,31].

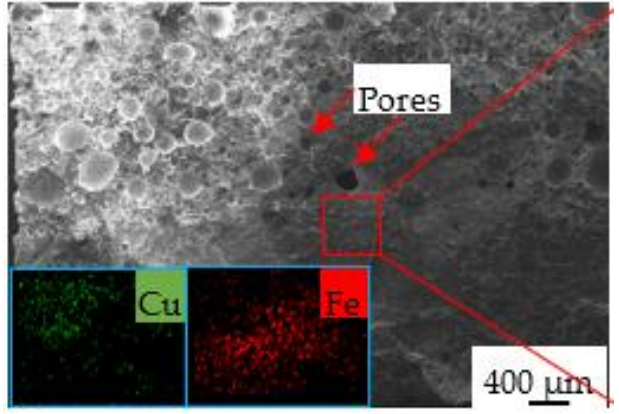

(a)

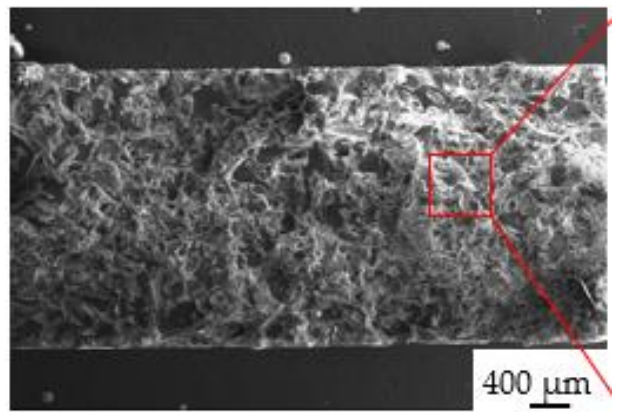

(c)

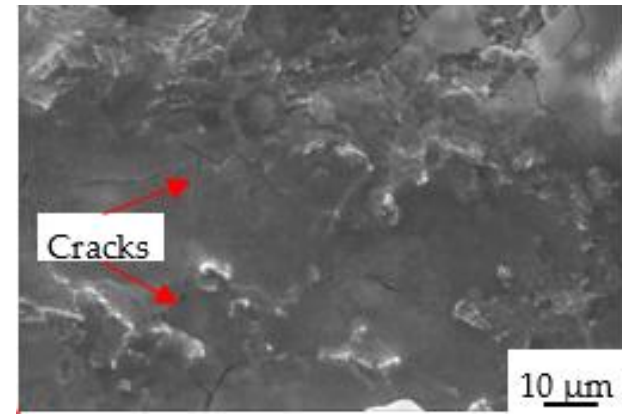

(b)

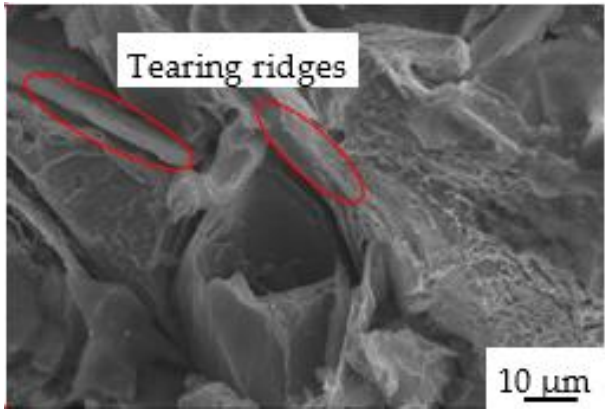

(d)

Figure 11. Fracture morphology of tensile samples without interlayer $(\mathbf{a}, \mathbf{b})$ and with the Inconel 718 interlayer $(\mathbf{c}, \mathbf{d})$.

\subsection{Microhardness}

Figure 12 depicts the variations in microhardness along the cross-section of samples with varying interlayers. In the samples without interlayers, the microhardnesses of the deposition layer (CuSn15) and the substrate (HT250) were $131.5( \pm 25) \mathrm{HV}_{0.2}$ and 
$180.1( \pm 5) \mathrm{HV}_{0.2}$, respectively. For the samples with the Inconel 718 interlayer, the microhardnesses of the CuSn15, Inconel 718, and HT250 were $192.0( \pm 38), 365.9( \pm 21)$ and $254.4( \pm 27) \mathrm{HV}_{0.2}$, respectively, signifying that adding the Inconel 718 interlayer enhanced the microhardnesses of the CuSn15 and HT250. In addition, an inconspicuous variability in microhardness distribution was obtained. The microhardness of the regions adjacent to the interface between the deposition layer and the interlayer or the substrate all manifested a tendency towards enhancement. However, the microhardness of the region adjacent to the interface between the interlayer and the substrate exhibited a descending trend.

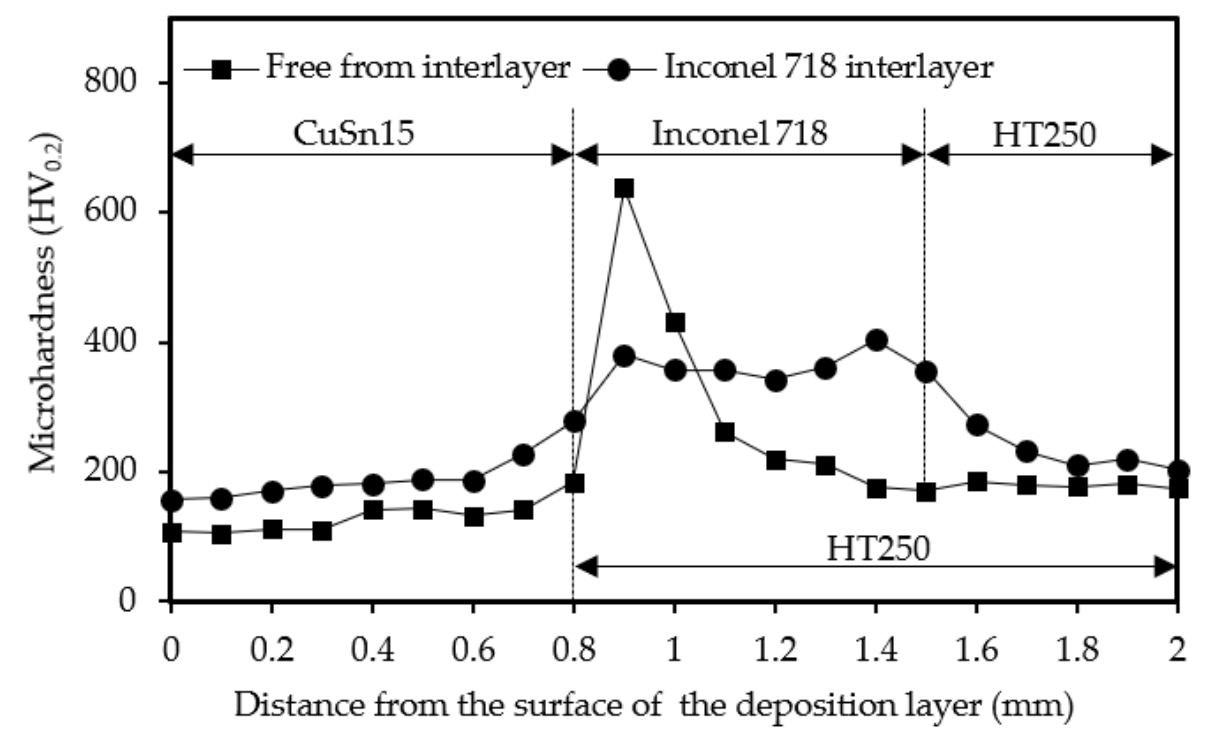

Figure 12. Variations in microhardness along the cross-section of samples with varying interlayers.

The improvement of microhardness in the interfacial regions between the deposition layer and the interlayer or the substrate was attributed to two aspects. For one thing, LDED is characterized by rapid heating and cooling, as well as layer-by-layer stacking formation, resulting in a phenomenon whereby the surfaces of the interlayer and the substrate were alternatively heated and cooled, just like quenching. In addition, the formation of martensite, the inhomogeneous distribution of the martensite, and the ferrite also resulted in a sharp improvement in microhardness [32-34]. Furthermore, $\mathrm{FeSn}_{2}$ with high hardness emerging in the interface regions also facilitated the improvement of microhardness. The Inconel 718 interlayer possessed a much higher microhardness than the general microhardness reported by previous researchers [35,36], which could also be attributed to the reason described above. Nevertheless, the interlayer regions adjacent to the interface with higher microhardness were diluted by the substrate (molten metal) during the LDED process, leading to decreased microhardness in the interface regions.

\subsection{Deposition of Impeller}

Figure 13 displays the morphology of the impeller after the LDED process and machining. The whole surface of the impeller (HT250) was covered by the deposition layer (CuSn15) with a thickness of approximately $2 \mathrm{~mm}$, generally exhibiting a superior thickness homogeneity, as shown in Figure 13a,b. The deposition layer was flat and smooth, and no remarkable cracks, holes and other typical defects could be observed. Additionally, as presented in Figure 13c, no deformation occurred in the regions where the three mounting holes are located, thus ensuring clamping precision during the subsequent machining process and guaranteeing assembly accuracy between the impeller and the matched shaft. To further improve the surface quality and to eventually satisfy the use requirements of the root blower, the deposition layer was then subjected to machining. The morphology after machining can be seen in Figure 13d,e. The machined surface was extremely smooth and 
was decorated by only a small number of micropores, indicating that the deposition layer possessed excellent forming quality.

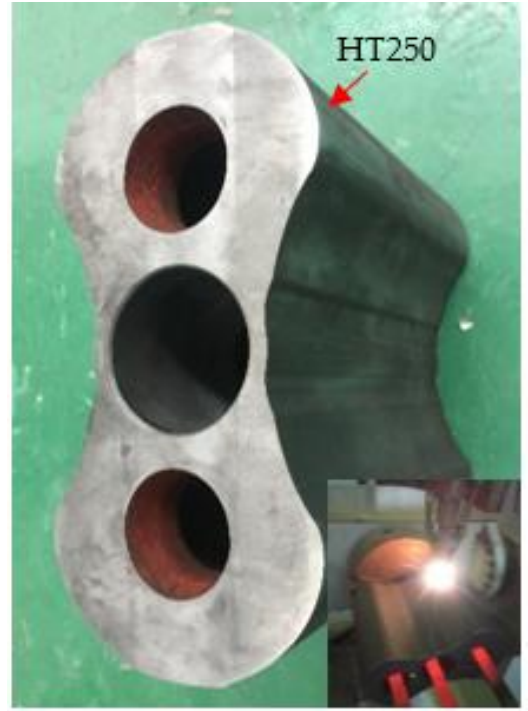

(a)

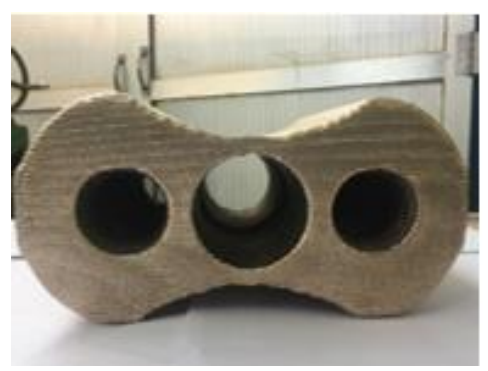

(c)

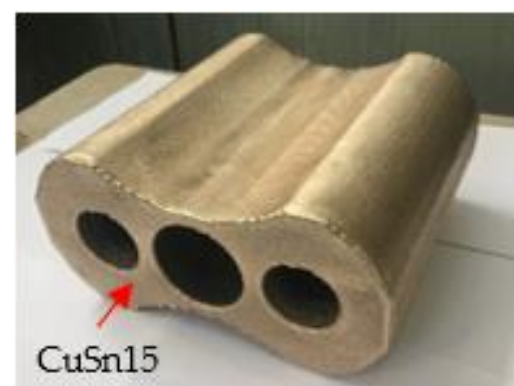

(b)

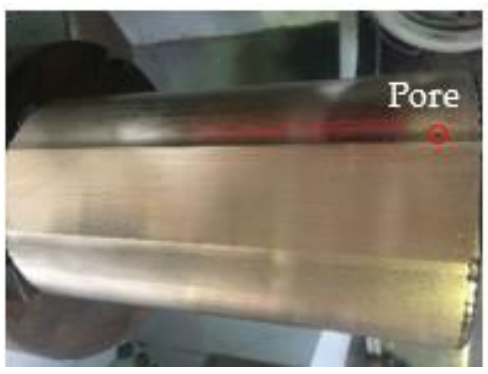

(d)

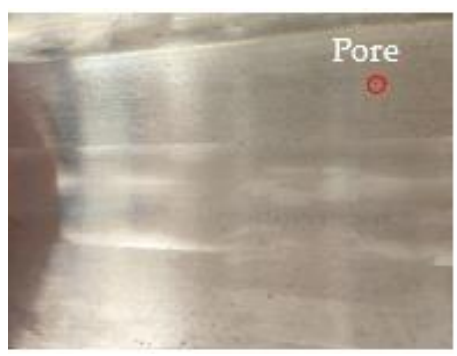

(e)

Figure 13. The morphology of the impeller before and after LDED and machining. (a) Blank impeller; (b) top surface; (c) end surface; $(\mathbf{d}, \mathbf{e})$ surface after machining. Note: Inconel 718 was firstly deposited on the HT250 and then CuSn15 was deposited on the Inconel 718.

\section{Conclusions}

1. A CuSn15 deposition layer and an HT250 substrate free from pores and cracks were both able to be obtained by virtue of parameter optimization in conjunction with the preheating and slow cooling processes.

2. Adding the Inconel 718 interlayer into the bonding region between the CuSn15 and HT250 eliminated the interfacial pores and cracks, facilitate the diffusion of the interfacial elements $(\mathrm{Cu}, \mathrm{Fe}, \mathrm{Ni})$, and enhanced the interfacial bonding strength. 
3. The interface between the HT250 and the CuSn15 contained $\mathrm{FeSn}_{2}$ phase, while the CuSn15-Inconel 718 and the Inconel 718-HT250 interfaces were mainly composed of $\mathrm{Ni}_{3} \mathrm{Sn}_{4}, \mathrm{Cr}_{5} \mathrm{Si}_{3}, \mathrm{FeSi}_{2}$, and $\mathrm{Cr}_{7} \mathrm{C}_{3}$.

4. Adding the Inconel 718 interlayer improved the microhardness of the CuSn15 and HT250 and altered the microhardness of the interfacial region due to the emergence of phases.

5. On the basis of the research results, the CuSn15 was finally deposited on an HT250 impeller with large size and complex structure, applied in a root blower.

Author Contributions: Conceptualization: H.L. and J.S.; methodology: H.L. and J.S.; software, H.L. and H.S.; formal analysis: H.L. and K.G.; investigation: H.L., K.G., J.S. and H.S.; writing-original draft preparation: H.L.; writing—review and editing: H.L. and J.S.; funding acquisition, K.G. and J.S. All authors have read and agreed to the published version of the manuscript.

Funding: This research was funded by the Key Research and Development Program of Shandong Province (Grant No.: 2019GGX104006), the Construction Engineering Special Fund of "Taishan Scholars" of Shandong Province (Grant No.: ts20190975).

Institutional Review Board Statement: Not applicable.

Informed Consent Statement: Not applicable.

Data Availability Statement: The data presented in this study are available on request from the corresponding author.

Conflicts of Interest: The authors declare no conflict of interest.

\section{References}

1. Saluja, R.S.; Singh, V. A fuzzy multi-attribute decision making model for selection of welding process for grey cast iron. Mater. Today Proc. 2020, 28, 1194-1199. [CrossRef]

2. Arthur, E.K.; Gikunoo, E.; Akromah, S.; Azeko, S.T.; Dzikunu, P. Alternative materials for grey cast iron corn-mill plates by computer-aided selection and weighted property methods: The case of Ghana. SN Appl. Sci. 2020, 2, 1398. [CrossRef]

3. Akande, I.; Fayomi, O.; Oluwole, O. Performance of composite coating on carbon steel-A Necessity. Energy Procedia 2019, 157, 375-383. [CrossRef]

4. Tong, X.; Zhou, H.; Ren, L.-Q.; Zhang, Z.-H.; Cui, R.-D.; Zhang, W. Thermal fatigue characteristics of gray cast iron with non-smooth surface treated by laser alloying of Cr powder. Surf. Coat. Technol. 2008, 202, 2527-2534. [CrossRef]

5. Riemschneider, E.; Bordeasu, I.; Mitelea, I.; Utu, I.D.; Crăciunescu, C.M. Morphology and mechanism of cavitation degradation of gray cast iron surfaces with lamellar graphite. Mater. Today Proc. 2021, 45, 4157-4160. [CrossRef]

6. Shirzadov, F.M.; Sadykhov, A.I. Tribological Properties of EN-GJV-400 Cast Iron after TIG Welding in a High-Frequency Magnetic Field. Russ. Eng. Res. 2020, 40, 908-911. [CrossRef]

7. Huang, J.; Liu, S.; Yu, S.; An, L.; Yu, X.; Fan, D.; Yang, F. Cladding Inconel 625 on cast iron via bypass coupling micro-plasma arc welding. J. Manuf. Process. 2020, 56, 106-115. [CrossRef]

8. Wang, H.Y.; Li, C.Y.; Ding, Y.M.; Li, J.; Chen, S.C. Experimental study on repairing of damaged cast iron cylinder heads by 3D printing arc welding system. IOP Conf. Ser. Mater. Sci. Eng. 2019, 474, 012032. [CrossRef]

9. Kellai, A.; Kahla, S.; Dehimi, S.; Babes, B. Microstructural and Mechanical Properties of Welding and Thermal Spraying Coatings on Ductile Cast Iron. Defect Diffus. Forum 2021, 406, 300-311. [CrossRef]

10. Ning, H.U.; Fan, Z.S. Process and properties of spray-aluminized coating on cast iron. Chin. J. Eng. 2017. [CrossRef]

11. Mirhedayatian, S.M.; Vahdat, S.E.; Jelodar, M.J.; Saen, R.F. Welding process selection for repairing nodular cast iron engine block by integrated fuzzy data envelopment analysis and TOPSIS approaches. Mater. Des. 2013, 43, 272-282. [CrossRef]

12. Li, B.; Zhu, H.; Qiu, C.; Gong, X. Laser cladding and in-situ nitriding of martensitic stainless steel coating with striking performance. Mater. Lett. 2020, 259, 126829. [CrossRef]

13. Zhu, H.; Li, Y.; Li, B.; Zhang, Z.; Qiu, C. Effects of Low-Temperature Tempering on Microstructure and Properties of the Laser-Cladded AISI 420 Martensitic Stainless Steel Coating. Coatings 2018, 8, 451. [CrossRef]

14. Ertugrul, O.; Enrici, T.M.; Paydas, H.; Saggionetto, E.; Boschini, F.; Mertens, A. Laser cladding of TiC reinforced 316L stainless steel composites: Feedstock powder preparation and microstructural evaluation. Powder Technol. 2020, 375, 384-396. [CrossRef]

15. Ren, Y.; Lin, X.; Yang, H.; Tan, H.; Chen, J.; Jian, Z.; Li, J.; Huang, W. Microstructural features of Ti-6Al-4V manufactured via high power laser directed energy deposition under low-cycle fatigue. J. Mater. Sci. Technol. 2021, 83, 18-33. [CrossRef]

16. Zhang, D.; Li, Y.; Wang, H.; Cong, W. An investigation on Ni4Ti3 phase precipitation and its effects in laser directed energy deposition of TiC-NiTi composites. Mater. Sci. Eng. A 2021, 809, 140976. [CrossRef] 
17. Li, Y.; Dong, S.; Yan, S.; Liu, X.; Li, E.; He, P.; Xu, B. Elimination of voids by laser remelting during laser cladding Ni based alloy on gray cast iron. Opt. Laser Technol. 2019, 112, 30-38. [CrossRef]

18. Li, Y.; Liu, X.; Dong, S.; Ren, X.; Yan, S.; Xu, B. Influence of laser power on interface characteristics and cracking behavior during laser remanufacturing of nodular cast iron. Eng. Fail. Anal. 2021, 122, 105226. [CrossRef]

19. Yi, P.; Zhan, X.; He, Q.; Liu, Y.; Xu, P.; Xiao, P.; Jia, D. Influence of laser parameters on graphite morphology in the bonding zone and process optimization in gray cast iron laser cladding. Opt. Laser Technol. 2019, 109, 480-487. [CrossRef]

20. Ocelík, V.; de Oliveira, U.; de Boer, M.; De Hosson, J. Thick Co-based coating on cast iron by side laser cladding: Analysis of processing conditions and coating properties. Surf. Coat. Technol. 2007, 201, 5875-5883. [CrossRef]

21. Pang, M.; Tan, W. Microscopic Characteristic Analysis and Crack Suppression of Laser-Surface Remelting of Vermicular-Graphite Cast-Iron Valve Seats. Laser Optoelectron. Prog. 2019, 56, 211402. [CrossRef]

22. Yi, P.; Fan, C.F.; Xu, P.Y.; Li, C.X. Analysis of Micro-Crack Inducing Mechanism by Graphite in Bond Area in Laser Repairing Grey Cast Iron. Appl. Mech. Mater. 2014, 607, 51-54. [CrossRef]

23. Yi, P.; Xu, P.; Fan, C.; Li, C.; Shi, Y. The Effect of Dynamic Local Self-Preheating in Laser Cladding on Grey Cast Iron. J. Mech. Eng. 2015, 61, 43-52. [CrossRef]

24. Maslov, V.A.; Kapustin, E.A.; Kulakov, A.M.; Yurenko, A.S.; Sadovskii, G.M. The state of the carbon in iron powders manufactured at the sulinsk metallurgical plant. Powder Met. Met. Ceram. 1975, 14, 6-9. [CrossRef]

25. Arias-González, F.; del Val, J.; Comesaña, R.; Penide, J.; Lusquiños, F.; Quintero, F.; Riveiro, A.; Boutinguiza, M.; Pou, J. Fiber laser cladding of nickel-based alloy on cast iron. Appl. Surf. Sci. 2016, 374, 197-205. [CrossRef]

26. Takeuchi, A.; Inoue, A. Classification of Bulk Metallic Glasses by Atomic Size Difference, Heat of Mixing and Period of Constituent Elements and Its Application to Characterization of the Main Alloying Element. Mater. Trans. 2005, 46, 2817-2829. [CrossRef]

27. Li, Y.; Dong, S.; Liu, X.; He, P.; Ren, X.; Yan, S.; Xu, B. Interface phase evolution during laser cladding of Ni-Cu alloy on nodular cast iron by powder pre-placed method. Opt. Laser Technol. 2021, 135, 106684. [CrossRef]

28. Li, J.; Liu, Y.; Kang, K.; Sun, Q.; Jin, P.; Liu, Y.; Cai, C.; Sun, Q. A novel approach to regulate energy allocation and melt flow in narrow gap laser welding with electromagnetic assisted wire wobbling. J. Mater. Process. Technol. 2021, 289, 116909. [CrossRef]

29. $\mathrm{Hu}, \mathrm{Y}$;; $\mathrm{Wu}, \mathrm{S}$.; Chen, L. Review on failure behaviors of fusion welded high-strength $\mathrm{Al}$ alloys due to fine equiaxed zone. Eng. Fract. Mech. 2019, 208, 45-71. [CrossRef]

30. Akdemir, A.; Kus, R.; Şimşir, M. Investigation of the tensile properties of continuous steel wire-reinforced gray cast iron composite. Mater. Sci. Eng. A 2011, 528, 3897-3904. [CrossRef]

31. Şimşir, M. Effect of heat treatment on fracture behavior of steel-wire-reinforced gray cast iron. Int. J. Fract. 2008, 151, 121-133. [CrossRef]

32. Soriano, C.; Leunda, J.; Lambarri, J.; Navas, V.G.; Sanz, C. Effect of laser surface hardening on the microstructure, hardness and residual stresses of austempered ductile iron grades. Appl. Surf. Sci. 2011, 257, 7101-7106. [CrossRef]

33. Zhao, H.; Li, J.; Zheng, Z.; Wang, A.; Zeng, D.; Miao, Y. The microstructures and tribological properties of composite coatings formed via PTA surface alloying of copper on nodular cast iron. Surf. Coat. Technol. 2016, 286, 303-312. [CrossRef]

34. Li, Y.; Dong, S.; Yan, S.; He, P.; Xu, B. Phase evolution of ductile iron during laser cladding processing. Surf. Coat. Technol. 2018, 339, 37-47. [CrossRef]

35. Cao, Y.; Bai, P.; Liu, F.; Hou, X.; Guo, Y. Effect of the Solution Temperature on the Precipitates and Grain Evolution of IN718 Fabricated by Laser Additive Manufacturing. Materials 2020, 13, 340. [CrossRef]

36. Alhuzaim, A.; Imbrogno, S.; Attallah, M.M. Controlling microstructural and mechanical properties of direct laser deposited Inconel 718 via laser power. J. Alloys Compd. 2021, 872, 159588. [CrossRef] 